\title{
Gene expression pattern of laser microdissected colonic crypts of adenomas with low grade dysplasia
}

\author{
S Lechner, U Müller-Ladner, B Renke, J Schölmerich, J Rüschoff, F Kullmann
}

Gut 2003;52:1148-1153

See end of article for authors' affiliations

Correspondence to: Associate Professor F Kullmann, Department of Internal Medicine I, Franz-Joseph-Strauss, Allee Regensburg 93042,

Germany;

frank.kullman@klinik.uniregensburg.de

Accepted for publication 20 February 2003

\begin{abstract}
Background and aims: Colorectal epithelial cells are prone to malignant transformation. Therefore, identification of differences in gene expression in the process from normal colonic crypts to adenomas with low grade dysplasia is essential for further insights into early tumorigenesis. To achieve this goal, a novel gene expression analysis strategy, screening for expressed transcripts in small histologically defined tissue samples, was performed.

Methods: First, laser mediated microdissection was used to isolate normal and adenomatous crypts from colonic cryosections. Then, nested RNA arbitrarily primed polymerase chain reaction (RAP-PCR) for differential display was performed to screen mRNA populations and to generate hybridisation probes for cDNA expression arrays. After evaluation of cDNA expression arrays, differential expression was confirmed at the protein level by immunohistochemistry.

Results: Evaluation of gene expression profiles of normal versus adenomatous colonic crypts of six different patients revealed, in general, dysregulation of up to $11 \%$ of all analysed genes (total number $\mathrm{n}=588$ ): specifically, p21-racl was upregulated in four of six patients, mitogen activated protein kinase (MAPK) p38 $\alpha$ in three of six patients, and interferon $\gamma$ receptor in three of six patients. Conversely, FAST kinase was found to be downregulated in three of six patients, p53 in three of six patients, and thrombospondin 2 in three of six patients.

Conclusions: For the first time, distinct gene expression profiles of dysplastic areas within colonic adenomas, using the combination of laser mediated microdissection with RAP-PCR and cDNA expression array, were shown. In these samples, upregulation of proliferation associated genes (ras-oncogene related $\mathrm{p} 21$-racl and MAPK $\mathrm{p} 38 \alpha$ ) as well as downregulation of apoptosis related genes (FAST kinase and p53) most likely reflects specific alterations in adenomas with low grade dysplasia. Based on upregulation of $\mathrm{p} 21$-rac 1 and MAPK $\mathrm{p} 38 \alpha$, activation of the MAPK pathway appears to be an early event in colonic carcinogenesis.
\end{abstract} defined microscopic tissue samples by introduction of laser mediated microdissection (LMM) $)^{2-4}$ has the advantage of more specific and precise analyses.

In this report, a novel gene expression analysis strategy combining the differential display approach of RNA arbitrarily

primed polymerase chain reaction (RAP-PCR) fingerprinting and cDNA expression array has been used to identify and validate gene expression profiles of distinct colonic crypts of adenomas with low grade dysplasia prepared by LMM.

\section{MATERIALS AND METHODS}

Tissue sections

Fresh tissue from normal colonic biopsies and adenomatous polyps during routine colonoscopy was immediately snap frozen in liquid nitrogen. All cryoblocks were stored at $-80^{\circ} \mathrm{C}$ until cutting.

Glass slides were membrane mounted (PEN membrane; PALM, Wolfratshausen, Germany) and poly-l-lysine coated $\left(0.2 \%\right.$ poly-l-lysine in sterile DEPC treated $\left.\mathrm{H}_{2} \mathrm{O}\right)$ under RNase free conditions. Cryosections $(5-8 \mu \mathrm{m})$ were prepared in a cryostat, dehydrated with ethanol/acetic acid (20/1) at $-20^{\circ} \mathrm{C}$ for 10 minutes, and stained with haematoxylin and eosin.

\section{Microdissection}

LMM was performed as described previously ${ }^{5}$ using a Robot Microbeam laser microscope (PALM). The tissue area of interest was positioned and cut out using a focused pulsed laser beam. Dissected areas were collected in the cap of a microcentrifuge tube via laser pressure catapulting. The cap with the

Abbreviations: LMM, laser mediated microdissection; RAP-PCR, RNA arbitrarily primed polymerase chain reaction; MAPK, mitogen activated protein kinase; IFGR, interferon gamma receptor; SSC, standard saline citrate; SDS, sodium dodecyl sulphate; AEC, 3-amino-9-ethylcarbazole. 

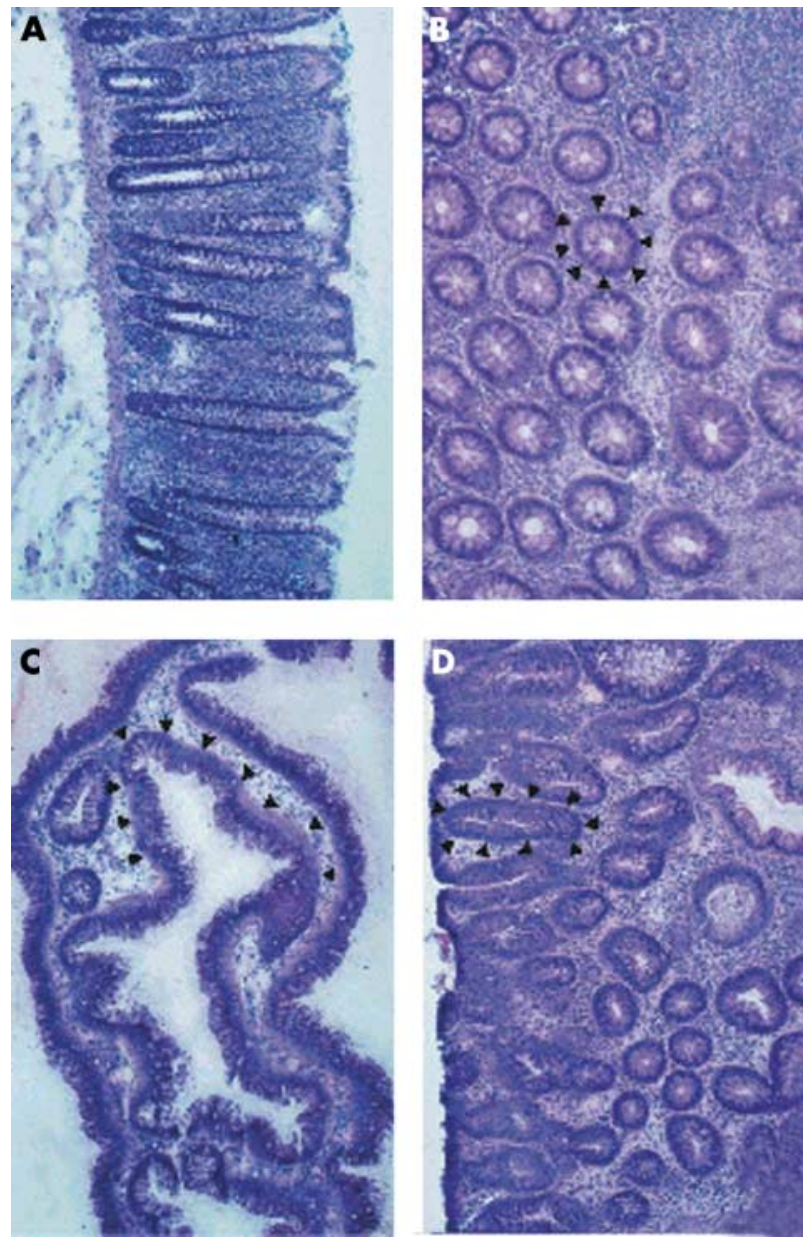

Figure 1 Haematoxylin-eosin stained sections of colon mucosa with normal (A, B) and adenomatous villous (C) or tubulous (D) colonic crypts (low grade dysplasia, D 1). Arrows mark objects for laser capture microdissection (B, C, D).

procured tissue was placed immediately on the microfuge tube containing $300 \mu \mathrm{l}$ of RLT lysis buffer of the RNeasy spin column purification kit (Qiagen, Hilden, Germany) and lysed by mixing.

\section{RNA extraction}

RNA was extracted by silica gel binding using the RNeasy spin column purification kit (Qiagen). To remove the remaining genomic DNA, total RNA was treated with DNase I (Qiagen) within the extraction column at room temperature for 30 minutes. Extraction was performed according to the manufacturer's instructions, and finally RNA was eluted with $30 \mu \mathrm{l}$ of RNase free water. The eluate was applied repeatedly to the column and spun through to increase the yield of RNA. ${ }^{5}$ The final concentration ranged from 0.8 to $2.3 \mathrm{ng} / \mu \mathrm{l}$.

\section{Atlas cDNA expression array}

Atlas cancer cDNA arrays (Clontech, Heidelberg, Germany) containing 588 known cancer related genes designed for the evaluation of different molecular expression patterns were used.

\section{Preparation of hybridisation probe}

The hybridisation probe was generated by amplification of the CDNA via nested RAP- PCR. Nested RAP-PCR was performed by amplification in two steps, as described previously. ${ }^{5}$ Briefly, reverse transcription for first strand synthesis was performed with total RNA using a 10mer arbitrary primer (OPN23 $5^{\prime}$-CAGGGGCACC-3'). RNA ( $2 \mathrm{ng}$ in a final volume of $30 \mu \mathrm{l}$ )
Table 1 Number and percentage of identically dysregulated genes analysing adenomatous (low grade dysplasia, D1) versus normal colonic crypts

\begin{tabular}{lrll}
\hline $\begin{array}{l}\text { Identically dysregulated } \\
\text { genes }\end{array}$ & 2 patients & 3 patients & 4 patients \\
\hline Upregulation & $13(2.2 \%)$ & $2(0.3 \%)$ & $1(0.2 \%)$ \\
Downregulation & $4(0.7 \%)$ & $3(0.5 \%)$ & - \\
\hline
\end{tabular}

Percentages were calculated as follows: differentially regulated genes divided by all analysed genes, $n=588$.

was mixed with $20 \mu \mathrm{l}$ of reverse transcriptase mixture for a final $50 \mu \mathrm{l}$ reaction containing $50 \mathrm{mM}$ Tris/ $\mathrm{HCl}, \mathrm{pH} 8.3,75 \mathrm{mM}$ $\mathrm{KCl}, 3 \mathrm{mM} \mathrm{MgCl}, 20 \mathrm{mM}$ DTT, $0.2 \mathrm{mM}$ dNTP, $2 \mu \mathrm{M}$ primer, and $100 \mathrm{U}$ MuLV reverse transcriptase (Promega, Madison, Wisconsin, USA). To exclude DNA contamination, a reverse transcriptase free control reaction was included in the RAP-PCR experiments. The reaction was carried out at $37^{\circ} \mathrm{C}$ for 60 minutes, after a five minute ramp from $25^{\circ} \mathrm{C}$ to $37^{\circ} \mathrm{C}$; inactivation of the reaction was done at $68^{\circ} \mathrm{C}$ for 15 minutes. Synthesised cDNA was purified by precipitation and resolved in $30 \mu \mathrm{l}$ of nuclease free water.

PCR for second strand synthesis was performed using a nested PCR strategy. In the first step, preamplification was achieved by 15 cycles with a 10mer arbitrary primer (OPN21 $5^{\prime}$ - ACCAGGGGCA-3'). The cDNA $(30 \mu \mathrm{l})$ was mixed with 20 $\mu \mathrm{l}$ of PCR mixture for final concentrations of $10 \mathrm{mM}$ Tris/ $\mathrm{HCl}$, $\mathrm{pH} 8.3,10 \mathrm{mM} \mathrm{KCl}, 4 \mathrm{mM} \mathrm{MgCl}, 0.2 \mathrm{mM}$ dNTPs, $4 \mu \mathrm{M}$ primer, and 2.5 U AmpliTaq DNA polymerase Stoffel fragment (Perkin Elmer, Norwalk, Connecticut, USA). Cycling conditions were $94^{\circ} \mathrm{C}$ for 30 seconds, $35^{\circ} \mathrm{C}$ for 30 seconds, and $72^{\circ} \mathrm{C}$ for 60 seconds.

The PCR product was purified by precipitation and resolved in $30 \mu \mathrm{l}$ of nuclease free water. A sample of the product of the first amplification step ( $10 \mu \mathrm{l})$ was used for the second amplification step with a nested 10mer arbitrary primer (OPN2 Inested 5'-CCAGGGGCAC- $3^{\prime}$ ). The reaction was carried out in a volume of $20 \mu \mathrm{l}$ containing $10 \mathrm{mM}$ Tris/HCl, pH 8.3, $10 \mathrm{mM} \mathrm{KCl}, 4 \mathrm{mM} \mathrm{MgCl}$, $0.2 \mathrm{mM}$ dNTPs (without dATP), $4 \mu \mathrm{M}$ primer, $2.5 \mathrm{U}$ AmpliTaq DNA polymerase Stoffel fragment (Perkin Elmer), and $28 \mu \mathrm{Ci}\left[\alpha-{ }^{32} \mathrm{P}\right] \mathrm{dATP}$ (3000 $\mathrm{Ci} / \mathrm{mmol}, 2.8 \mu \mathrm{l}$; Amersham, Freiburg, Germany). Cycling conditions were 35 cycles of $94^{\circ} \mathrm{C}$ for 30 seconds, $35^{\circ} \mathrm{C}$ for $30 \mathrm{sec}$ onds, and $72^{\circ} \mathrm{C}$ for 60 seconds. All reactions were carried out in duplicate to test the reproducibility and stability of the RNA fingerprint.

After confirmation of the success of the RAP-PCR (via gel electrophoresis and autoradiography ${ }^{5}$ ), the PCR reaction was purified from unincorporated ${ }^{32} \mathrm{P}$ labelled nucleotides and small DNA fragments $(<0.1 \mathrm{~kb})$ by column chromatography using NucleoSpin columns (Clontech), as outlined by the manufacturer.

\section{Hybridisation}

The RAP-PCR product was hybridised to the Atlas human cDNA expression array membranes, as published recently. ${ }^{5}$

\section{Wash}

Filters were washed three times in wash solution $1(2 \times$ standard saline citrate (SSC) and $2 \%$ sodium dodecyl sulphate (SDS)) for 30 minutes at $68^{\circ} \mathrm{C}$ each. Two washing steps were performed with wash solution $2(0.1 \times$ SSC and $0.5 \%$ SDS $)$ at $68^{\circ} \mathrm{C}$ for 20 minutes and one step for five minutes at room temperature in $2 \times$ SSC and then exposed to a PhosphorImager- Screen (Molecular Dynamics, Sunnyvale, California, USA) for approximately five days.

\section{Data analysis}

Analysis of the scanned Phosphor-Imager-Screen was performed using Ambis software (ImageQuant, Molecular 
Table 2 Differentially expressed genes in adenomatous (low grade dysplasia, D1) versus normal colonic samples (differentially regulated in at least $3 / 6$ patients)

\begin{tabular}{|c|c|c|c|}
\hline Gene (accession No) & $\begin{array}{l}\text { Upregulated (fold } \\
\text { increase) }\end{array}$ & $\begin{array}{l}\text { Downregulated (fold } \\
\text { decrease) }\end{array}$ & Regulation \\
\hline $\begin{array}{l}\text { p21-rac1; ras related protein TC25 } \\
\text { (M29870, M31467) }\end{array}$ & $\begin{array}{l}2.4 \\
3.4 \\
3.0 \\
4.5 \\
\quad(M=3.3)\end{array}$ & & $\uparrow 4(6)^{*}$ \\
\hline MAPK p38 (L35253, L35263) & $\begin{array}{l}2.8 \\
3.3 \\
3.5 \\
\quad(M=3.2)\end{array}$ & & $\uparrow 3(6)$ \\
\hline IFGR (A09781) & $\begin{array}{l}3.7 \\
4.0 \\
2.8 \\
\quad(M=3.5)\end{array}$ & & $\uparrow 3(6)$ \\
\hline TSP2 (L12350) & & $\begin{array}{l}8.3 \\
8.7 \\
9.8 \\
\quad(M=8.9)\end{array}$ & $\downarrow 3(6)$ \\
\hline $\begin{array}{l}\text { p53 cellular tumour antigen (M14694, } \\
\text { M14695) }\end{array}$ & & $\begin{array}{r}2.5 \\
3.2 \\
28.2 \\
\quad(M=11.3)\end{array}$ & $\downarrow 3(6)$ \\
\hline FAST kinase (X86779) & & $\begin{array}{l}4.6 \\
9.9 \\
2.5 \\
\quad(M=5.7)\end{array}$ & $\downarrow 3(6)$ \\
\hline
\end{tabular}

Dynamics) and gene expression evaluation was performed using AtlasImage 2.0 software which was developed specifically for analysis of the Atlas cDNA expression arrays (Clontech).

\section{Confirmation of differential expression}

The first step for confirmation of differential expression was achieved by performing each experiment in duplicate (microdissection), in two parallel reactions (amplification and hybridisation) under the same conditions, and only those hybridisation results which indicated differential expression (twofold or more dysregulation) in both reactions were regarded to be of further interest.

In the second step, immunohistochemistry was performed with polyclonal antibodies against p2 1-Racl (Santa Cruz Biotechnology, Santa Cruz, California, USA) and monoclonal antibodies against interferon gamma receptor (IFGR; Santa Cruz Biotechnology) using the AEC (3-amino-9ethylcarbazole) substrate kit for peroxidase (Vector Laboratories, Burlingame, California, USA) to confirm the differential expressed genes at the protein level. Snap frozen sections were cut $(4-6 \mu \mathrm{m})$, fixed for five minutes in acetone, and covered with a $4 \%$ non-fat dry milk $2 \%$ normal goat serum buffer for 30 minutes at room temperature to block non-specific binding. After rinsing in Tris $\mathrm{NaCl}, \mathrm{pH} \mathrm{7.6}$, the slides were incubated for 45 minutes at room temperature with the primary antibodies diluted 1:50-1:200 in Tris $\mathrm{NaCl}$ containing $2 \%$ non-fat dry milk. The slides were rinsed in Tris $\mathrm{NaCl}$ and incubated for 30 minutes at room temperature with a secondary biotinylated antimouse and antirabbit IgG antibody, respectively (Pharmingen, San Diego, California, USA) in a 1:400 dilution in Tris $\mathrm{NaCl}$ containing 2\% non-fat dry milk. Incubation with the AEC substrate (Vector Laboratories) was performed for 30 minutes at room temperature. Colour development (varying from 10 to 30 minutes) was stopped under microscopic examination by washing with water. After staining with haematoxylin, the slides were mounted immediately (Gel Mount, Biomeda, Foster City, California, USA).

\section{RESULTS}

\section{Histology and LMM}

LMM was used to isolate colonic crypts of normal and adenomatous (low grade dysplasia, D1) mucosa of six different patients. Characteristics for classification as normal or adenomatous crypt, respectively, were the following: crypt size, crypt shape, thickness of the epithelial layer, quantity of cytoplasm, and existence of goblet cells (fig 1). p21-racl

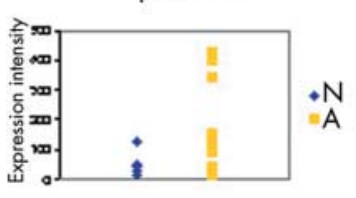

MARK $\mathrm{p} 38 \propto$

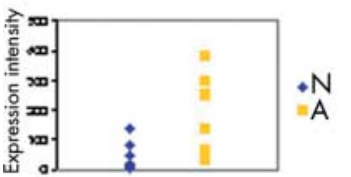

IFGR

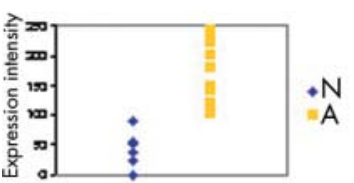

TSP2

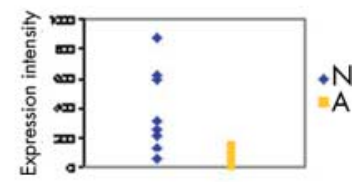

p53

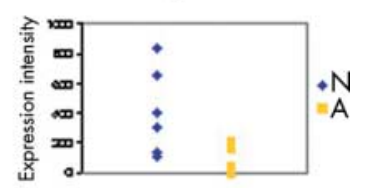

FAST-kinase

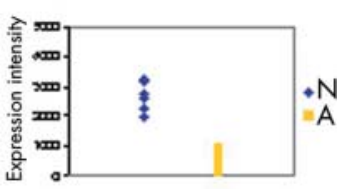

Figure 2 Expression intensities of $\mathrm{p} 21$-rac 1 , mitogen activated protein kinase (MAPK) p38a, interferon gamma receptor (IFGR), thrombospondin 2 (TSP2), p53, and FAST kinase. Each symbol represents one expression intensity of one array hybridisation. All patients are included, but there is large overlap of expression values resulting in a lower number of visible symbols. $\mathrm{N}$, normal colonic crypts; A, adenomatous colonic crypts (low grade dysplasia, D1). 

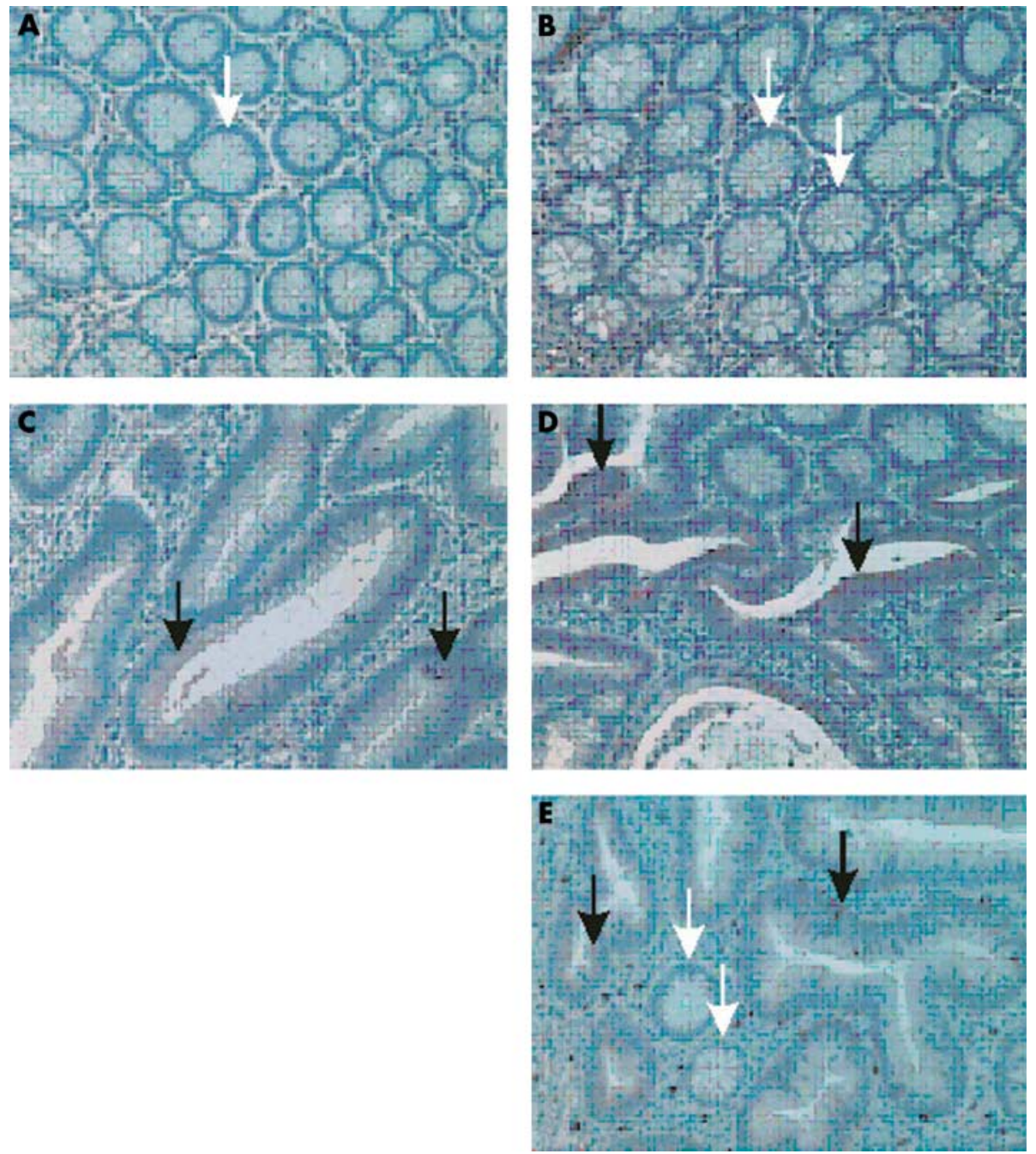

Figure 3 Immunohistochemical staining using antibodies against interferon gamma receptor (IFGR) (A, B) and against p2 1-racl (C, D, E). (A, C) Normal colonic crypts; (B, D, E) mainly adenomatous colonic crypts with low grade dysplasia (D 1). Black arrows show positive staining (red-brown), and white arrows show crypts without staining; negative controls showed no staining. Original magnification 200-fold.

\section{cDNA array hybridisation and evaluation of differential gene expression}

Each array experiment revealed approximately 55-120 hybridisation events (out of 588 possible events). Using the AtlasImage 2.0 software, these events could be clearly coordinated with the cDNA spots.

Evaluation of the cDNA expression arrays of all six patients revealed reproducible differential expression of 68 genes (11.6\% of all 588 analysed genes) comparing adenomatous versus normal colonic crypts; $7.7 \%$ of all 588 analysed genes were only differentially expressed in one of the six analysed patients. The remaining 3.9\% of the differentially expressed genes were dysregulated in 2-4 patients (table 1).

Only those genes which were dysregulated in at least three of six dysplastic compared with normal colonic crypts of a patient were further examined ( $1 \%$ of all analysed 588 genes, marked in table 1). The genes were: p2l-racl, mitogen activated protein kinase (MAPK) p38, IFGR, thrombospondin 2 , p53, and FAST kinase. In table 2, expression levels of the dysregulated genes are listed. Figure 2 demonstrates differences in expression intensities in normal and adenomatous colonic mucosa.

\section{Validation of array data with immunohistochemistry}

To further confirm the reliability of our array data, we performed immunohistochemical analysis of IFGR and p21-racl protein using tissue from the same patients. Similar to the differential expression pattern observed with the cDNA array, normal crypt cells showed no or minimal immunoreactivity for IFGR (fig 3A) or p21-racl (fig 3C) whereas crypt cells of Dl dysplastic lesions showed strong immunoreactivity for these proteins (fig 3B, D, E). These results further support the reliability of our array data and demonstrate the specific location of IFGR and p21-racl expression in early adenoma.

\section{DISCUSSION}

Using the combination of LMM, RAP-PCR, ${ }^{67}$ and CDNA expression array, ${ }^{59}$ we showed for the first time distinct gene expression profiles of areas of low grade dysplasia within colonic adenomas. This strategy provides an unique opportunity to relate gene expression of subpopulations of cells to their actual tissue environment. Moreover, using LMM, genetic analysis of pure and very small cell populations is possible and the limitations associated with in vivo and in vitro studies can be minimised.

When we analysed six individual patients, distinct alterations in gene expression of normal versus low grade dysplastic adenomas (D1) were demonstrated. Upregulation of proliferation associated genes (ras-oncogene related p2l-racl and MAPK p38 $\alpha$ ) as well as downregulation of apoptosis related genes (FAST kinase and p53) was demonstrated at the mRNA level in adenomas with low grade dysplasia.

However, thrombospondin 2, whose expression is generally associated with tumour defence via regulation of 
Table 3 Differentially expressed genes in adenomatous (low grade dysplasia, D1) versus normal colonic samples (differentially regulated in at least $2 / 6$ patients)

\begin{tabular}{|c|c|c|c|}
\hline Gene (accession No) & Upregulated (fold increase) & $\begin{array}{l}\text { Downregulated (fold } \\
\text { increase) }\end{array}$ & Regulation \\
\hline DNA-PK; DNA-PKCS (U35835) & $\begin{array}{r}4.4 \\
11.5 \\
\quad(M=7.95)\end{array}$ & & $\uparrow 2(6)^{*}$ \\
\hline DNA topoisomerase II alpha (170kDa) (J04088) & $23^{2.6}(M=12.8)$ & & $\uparrow 2(6)$ \\
\hline $\begin{array}{l}\text { rho GDP dissociation inhibitor 2; LY-GDI; ARHGDIB; } \\
\text { GDID4 (L20688) }\end{array}$ & $\begin{array}{r}3.0 \\
24.0 \\
(M=13.5)\end{array}$ & & $\uparrow 2(6)$ \\
\hline Laminin beta 1 (M61916) & $\begin{array}{l}4.4 \\
5.5 \\
(M=4.95)\end{array}$ & & $\uparrow 2(6)$ \\
\hline $\begin{array}{l}\text { Catenin (cadherin associated protein) beta } 1(88 \mathrm{kDa}) \\
(\mathrm{X87838)}\end{array}$ & $\begin{array}{r}2.2 \\
27.6 \\
(M=14.9)\end{array}$ & & $\uparrow 2(6)$ \\
\hline Cyclin dependent kinase 6 X66365) & $\begin{array}{r}6.8 \\
12.1 \\
(M=9.45)\end{array}$ & & $\uparrow 2(6)$ \\
\hline $\begin{array}{l}\text { CDKN1A; melanoma differentiation associated protein 6; } \\
\text { CIP1; WAF1 (U09579) }\end{array}$ & $\begin{array}{l}29.5 \\
42.5 \\
(M=36.0)\end{array}$ & & $\uparrow 2(6)$ \\
\hline $\begin{array}{l}\text { v-erb-b2 avian erythroblastic leukaemia viral oncogene } \\
\text { homolog } 3 \text { (M29366) }\end{array}$ & $\begin{array}{r}13.5 \\
4.0 \\
\quad(M=8.75)\end{array}$ & & $\uparrow 2(6)$ \\
\hline BARD1 (U76638) & $\begin{array}{l}2.6 \\
40.0 \\
(M=21.3)\end{array}$ & $\begin{array}{l}5.4 \\
7.4 \\
(M=6.4)\end{array}$ & $\uparrow 2(6) / \downarrow 2(6)$ \\
\hline $\begin{array}{l}\text { Hepatoma derived growth factor (high mobility group } \\
\text { protein 1- like) (D16431) }\end{array}$ & $\begin{array}{l}2.8 \\
7.8 \\
(M=5.3)\end{array}$ & 7.5 & $\uparrow 2(6) / \downarrow 1(6)$ \\
\hline Inhibitor of growth 1 family member 1 (AF001954) & 29.7 & $\begin{array}{l}9.45 \\
5.6 \\
(M=7.53)\end{array}$ & $\uparrow 1(6) / \downarrow 2(6)$ \\
\hline Integrin alpha 6; VLA6, CD49F antigen (X53586) & 2.25 & $\begin{array}{r}2.9 \\
51.0 \\
\\
(M=26.95)\end{array}$ & $\uparrow 1(6) / \downarrow 2(6)$ \\
\hline $\begin{array}{l}\text { Urokinase-type plasminogen activator receptor } \\
\text { GPI-anchored form precursor (U-PAR); monocyte } \\
\text { activation MO3; CD87 antigen (U08839) }\end{array}$ & & $\begin{array}{r}24.7 \\
2.6 \\
\quad(M=13.65)\end{array}$ & $\downarrow 2(6)$ \\
\hline $\begin{array}{l}\text { Type II cytoskeletal } 8 \text { keratin (KRT8); cytokeratin } 8 \text { (K8; } \\
\text { CK8) (M34225) }\end{array}$ & & $\begin{array}{l}2.4 \\
3.3 \\
(M=2.85)\end{array}$ & $\downarrow 2(6)$ \\
\hline
\end{tabular}

Values represent the mean up- or downregulation of all experiments in each patient.

*2 (6) indicates 2 of 6 patients regulated differentially.

$\mathrm{M}$, median; DNA-PK, DNA dependent protein kinase; DNA-PKCS, DNA-PK catalytic subunit; CDKN1A cyclin dependent kinase inhibitor 1 A; CIPI,

CDK-interacting protein 1; BARD1, BRCA1 associated RING domain.

angiogenesis, ${ }^{10}$ was found to be downregulated in low grade dysplastic lesions. This downregulation may also be involved in adenoma/tumour development.

One of the pathways thought to be activated in colonic tumorigenesis is the RAS/MAPK pathway which plays an important role in regulation of proliferation and transcription. At the end of the MAPK signalling cascade, activation of transcription factors such as ATF2, c-Jun, c-Fos, CHOP/GADD153, Max, or MEF $2{ }^{11}$ is essential. Different genes in this signalling cascade were identified as being upregulated in low grade dysplastic adenomas: p21-racl (see table 2 and fig 2), MAPK p38 $\alpha$ (see table 2 and fig 2), rho-GDP dissociation inhibitor 2 (see table 3, upregulated in 2/6 patients), p2 1 -activated kinase $\alpha$, and MAPK 6 (data not shown, both upregulated in $1 / 6$ patients).

p21-racl is a member of the RAS superfamily of the small GTP binding proteins and can activate protein kinases such as JNK, SAPK, or MAPK p38. MAPK p38 $\alpha$, in turn, is an activator of different transcription factors. ${ }^{11}$

Based on upregulation of p21-racl and MAPK p38 $\alpha$ in low grade dysplastic adenomas, activation of the MAPK pathway appears to be an early event in colonic carcinogenesis. This activation seems to be characteristic for low grade dysplastic lesions as Wang and colleagues ${ }^{12}$ have shown that MAPK p38, 
ERK1, ERK2, and JNK, all members of the MAPK pathway, are downregulated in carcinomas, which appear late in colon carcinogenesis.

The results of the present study also provide the basis for a more general use of laser microdissection in colon cancer histomolecular analysis. We believe that examination of adenomas with low grade dysplasia not only reveals the initial steps towards established colon carcinoma but most likely will facilitate identification of subgroups of patients at high risk for more rapid development of malignancy. Moreover, understanding of these initial steps may also provide the rationale for therapeutic strategies in more advanced stages of the disease-for example, the development of specific drugs following colon surgery with a high risk for local or distant metastases based on severe gene dysregulation already operative in macroscopically non-visible premalignant lesions (for example, aberrant crypt foci).

We have shown that the combination of RAP-PCR and cDNA expression array together with LMM offers the possibility of gaining insight into the early molecular events in colon carcinogenesis. Our findings indicate that p21-racl and MAPK p38 are interesting candidate genes potentially involved in key mechanisms leading to malignant transformation in the colonic crypt.

\section{ACKNOWLEDGEMENTS}

The authors wish to thank Olga Wiesner, Wibke Ballhorn, and Elena Neumann for excellent technical assistance. This research was funded by the Deutsche Forschungsgemeinschaft (Ku 1024/6-3, Mu 1383/1-3 and $\mathrm{Mu} 1383 / 3-3)$.
Authors' affiliations

S Lechner, U Müller-Ladner, J Schölmerich, F Kullmann, Department of Internal Medicine I, University of Regensburg, D-93042 Regensburg, Germany

B Renke, J Rüschoff, Institute of Pathology, Klinikum Kassel, D-34125

Kassel, Germany

\section{REFERENCES}

1 Fearon ER, Vogelstein B. A genetic model for colorectal tumorigenesis. Cell 1990;61:759-67.

2 Emmert-Buck MR, Bonner RF, Smith, et al. Laser capture microdissection. Science 1996;274:998-1001.

3 Simone NL, Bonner RF, Gillespie JW, et al. Laser-capture microdissection: opening the microscopic frontier to molecular analysis. Trends Genet 1998;14:272-6.

4 Suarez-Quian CA, Goldstein SR, Pohida T, et al. Laser capture microdissection of single cells from complex tissues. Biotechniques 1999;26:328-35

5 Lechner S, Müller-Ladner U, Neumann E, et al. Use of simplified transcriptors for the analysis of gene expression profiles in

laser-microdissected cell populations. Lab Invest 2001;81:1233-42. 6 McClelland M, Mathieu-Daude F, Welsh J. RNA fingerprinting and differential display using arbitrarily primed PCR. Trends Genet 1995;11: 242-6

7 Welsh J, Chada K, Dalal SS, et al. Arbitrarily primed PCR fingerprinting of RNA. Nucleic Acids Res 1992;20:4965-70.

8 Trenkle T, Welsh J, Jung B, et al. Non-stoichiometric reduced complexity probes for cDNA arrays. Nucleic Acids Res 1998;26:3883-91.

9 Neumann E, Kullmann F, Judex $M$, et al. Identification of differentially expressed genes in rheumatoid arthritis by a combination of cDNA array and RAP-PCR. Arthritis Rheum 2002;46:52-63.

10 Streit M, Riccardi L, Velasco P, et al. Thrombospondin-2: a potent endogenous inhibitor of tumor growth and angiogenesis. Proc Natl Acad Sci US A 1999:96:14888-93.

11 Kyriakis JM, Avruch J. Mammalian mitogen-activated protein kinase signal transduction pathways activated by stress and inflammation. Physiol Rev 2001;81:807-69.

12 Wang Q, Ding Q, Dong Z, et al. Downregulation of mitogen-activated protein kinases in human colon cancers. Anticancer Res $2000 ; 20: 75-83$ 